\title{
Direct Surgical Treatment of Giant Intracranial Aneurysms on the Anterior Communicating Artery or Anterior Cerebral Artery
}

\author{
Hideki NAKAJIMA, ${ }^{1}$ Hiroyasu KAMIYAMA, ${ }^{1}$ Toshitaka NAKAMURA, ${ }^{1}$ \\ Katsumi TAKIZAWA, ${ }^{1}$ and Kenji OHATA ${ }^{2}$
}

\author{
${ }^{1}$ Department of Neurosurgery, Asahikawa Red Cross Hospital, Asahikawa, Hokkaido; \\ ${ }^{2}$ Department of Neurosurgery, Osaka City University Graduate School of Medicine, Osaka, Osaka
}

\begin{abstract}
Giant intracranial aneurysms on the anterior communicating artery (AComA) or anterior cerebral artery (ACA) are rare and treatment is very difficult. The outcome of direct surgical treatment of giant intracranial aneurysms on the ACom A or ACA using vascular reconstruction techniques was assessed in five patients treated between 2006 and 2009 . In all five patients, cerebral revascularization of ACA territory was performed to ensure blood flow in the distal ACA prior to treating the aneurysm. Trapping was performed in two patients, trapping and partial removal of the aneurysm in two patients, and total removal of the aneurysm with reanastomosis of ACA in one patient. Minor ischemic complication due to perforator ischemia was recognized in one patient and frontal lobe contusion in one patient. All patients were able to achieve functionally favorable outcome (modified Rankin scale 0 or 1). Insurance cerebral revascularization of the ACA territory enabled appropriate direct surgical strategies for giant AComA or ACA aneurysms tailored to each individual case, including trapping with or without removal of the aneurysm, and reanastomosis of the ACA with removal of the aneurysm.
\end{abstract}

Key words: giant intracranial aneurysm, anterior communicating artery, anterior cerebral artery, direct surgery, bypass surgery

\section{Introduction}

Giant intracranial aneurysm, defined as $25 \mathrm{~mm}$ or larger in maximum diameter, is a life-threatening lesion with a mortality rate of $65-85 \%$ within 2 years has been reported., ${ }^{1,3,9)}$ Treatment of giant intracranial aneurysms located on the anterior communicating artery (AComA) or anterior cerebral artery (ACA) can be very difficult, and is not always successful. ${ }^{2,5-8,10-15)}$ This study reviewed the treatment of our series of giant intracranial aneurysms of the AComA or ACA using vascular reconstruction techniques.

\section{Methods}

A total of 1232 aneurysms were treated with direct surgery at the Asahikawa Red Cross Hospital be- tween 2006 and 2009. Of these, five aneurysms were AComA or ACA aneurysms (Table 1). Four aneurysms were located on the AComA and one aneurysm on the distal ACA. None of the patients, 3 males and 2 females aged 26 to 70 years (mean 55.4 years), had received previous treatment for aneurysm. The mean aneurysm diameter was 31.0 $\mathrm{mm}(25-40 \mathrm{~mm})$ on imaging. The shapes of the aneurysms were saccular in two and thrombosed in three cases. No ruptured aneurysm was found. Four patients presented with no symptom and one patient had mild disorientation caused by compression symptom from the aneurysm.

Aneurysms were approached by bifrontal craniotomy followed by the interhemispheric approach in all patients. Cerebral revascularization of the ACA territory was performed to ensure blood supply to the distal ACA prior to treating the

Received February 8, 2012; Accepted May 22, 2012

Author's present address: H. Nakajima, MD, Department of Neurosurgery, Osaka City General Hospital, Osaka, Osaka, Japan. 
Table 1 Summary of giant intracranial aneurysms on the anterior communicating artery (AComA) or anterior cerebral artery (ACA)

\begin{tabular}{|c|c|c|c|c|c|c|c|c|}
\hline $\begin{array}{l}\text { Case } \\
\text { No. }\end{array}$ & $\begin{array}{l}\text { Age } \\
\text { (yrs)/ } \\
\text { Sex }\end{array}$ & Site & $\begin{array}{c}\text { Size } \\
(\mathrm{mm})\end{array}$ & Shape & Onset & Treatment & Complication & $\begin{array}{l}\mathrm{mRS} \\
\text { score }\end{array}$ \\
\hline 2 & $66 / \mathrm{F}$ & AComA & 25 & saccular & incidental & $\begin{array}{l}\text { trapping with } \mathrm{A}_{3}-\mathrm{A}_{3} \\
\text { anastomosis }\end{array}$ & none & 0 \\
\hline 3 & $60 / \mathrm{M}$ & AComA & 30 & thrombosed & incidental & $\begin{array}{l}\text { trapping and partial } \\
\text { removal with bilateral } \mathrm{A}_{3} \\
\text { double anastomosis using } \\
\text { RA graft }\end{array}$ & none & 0 \\
\hline 4 & $26 / \mathrm{M}$ & AComA & 35 & thrombosed & incidental & $\begin{array}{l}\text { trapping and partial } \\
\text { removal with bilateral } \mathrm{A}_{3} \\
\text { double anastomosis using } \\
\text { RA graft }\end{array}$ & $\begin{array}{r}\text { frontal lobe } \\
\text { contusion }\end{array}$ & 1 \\
\hline 5 & $70 / \mathrm{F}$ & $\begin{array}{l}\text { distal } \\
\text { ACA }\end{array}$ & 40 & thrombosed & $\begin{array}{l}\text { compressive } \\
\text { symptom }\end{array}$ & $\begin{array}{l}\text { total removal and } \\
\text { reanastomosis of ACA } \\
\text { with } A_{3}-A_{3} \text { anastomosis }\end{array}$ & none & 0 \\
\hline
\end{tabular}

mRS: modified Rankin scale, RA: radial artery.

aneurysm. Trapping with or without removal of the aneurysm was carried out and reanastomosis of ACA was performed when possible.

\section{Results}

$\mathrm{A}_{3}-\mathrm{A}_{3}$ side-to-side anastomosis was performed in three patients and bilateral $\mathrm{A}_{3}$ double anastomosis using a radial artery (RA) graft in two patients as an insurance bypass prior to approaching the aneurysm. Trapping was carried out in two patients, trapping with partial removal in two patients, and total removal with reanastomosis of the ACA in one patient (Table 1). Bilateral $\mathrm{A}_{3}$ double anastomosis using an RA graft was performed for fear of bilateral $\mathrm{A}_{2}$ occlusion. The RA graft was removed and a superficial temporal artery (STA) was removed as a Y graft. The proximal end of STA-RA graft-Y graftbilateral $\mathrm{A}_{3}$ portion bypass was performed and trapping with partial removal of the aneurysm was carried out in these patients. Reconstruction of the perforator was performed in one patient (Case 1), and anticoagulant and antiplatelet agents were administered intra- and postoperatively in this patient.

Minor ischemic complication due to perforating artery injury was recognized in one patient and mild frontal lobe contusion in another. New permanent neurological deficits persisted on one patient. No other complication was recognized and all patients had a functionally favorable outcome (modified Rankin scale 0 or 1 ) (Table 1 ).

Magnetic resonance (MR) imaging including diffusion-weighted imaging and three-dimensional computed tomography (3D CT) angiography were

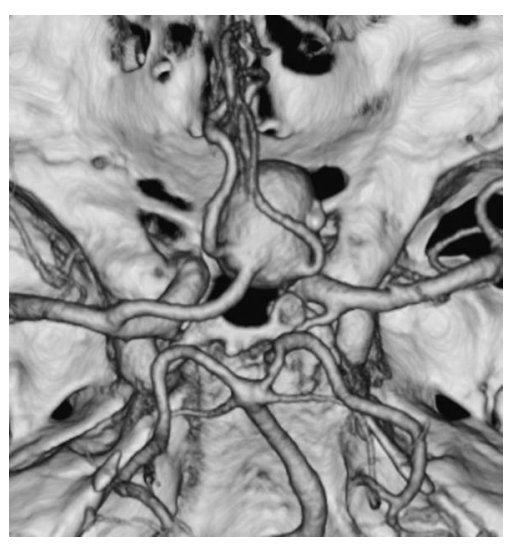

Fig. 1 Case 1. Preoperative axial three-dimensional computed tomography angiogram showing a giant saccular anterior communicating artery aneurysm, $25 \mathrm{~mm}$ in maximum diameter.

performed within 7 days after the surgery. Longterm follow-up study used 3D CT angiography and/or MR imaging every 6 months. The aneurysms were not visualized and the bilateral ACAs were revealed clearly in all patients throughout the follow up.

\section{Representative Cases}

Case 1: A 55-year-old man presented with no neurological deficit. A giant saccular aneurysm on the AComA, $25 \mathrm{~mm}$ in maximum diameter, was found incidentally (Fig. 1). Direct surgery of the aneurysm was planned. $\mathrm{A}_{3}-\mathrm{A}_{3}$ side-to-side anastomosis was performed to ensure blood flow in the distal ACA prior to treating the aneurysm. A perforator was 


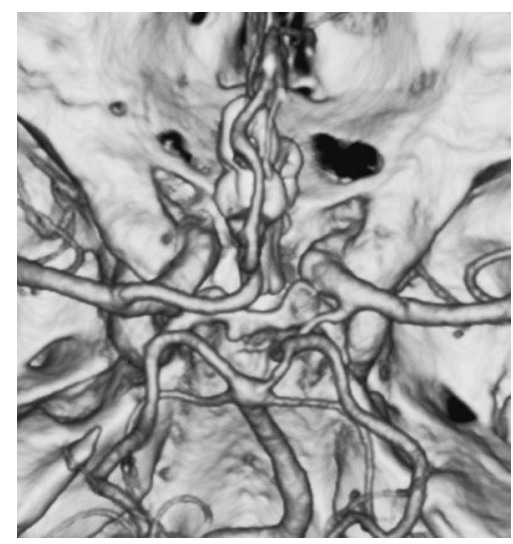

Fig. 2 Case 1. Postoperative axial three-dimensional computed tomography angiogram showing the giant anterior communicating artery aneurysm was not visualized.

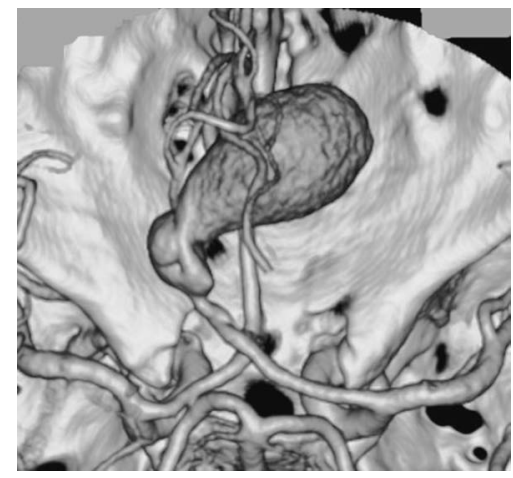

Fig. 3 Case 2. Preoperative axial three-dimensional computed tomography angiogram showing a giant partially thrombosed distal anterior cerebral artery aneurysm, with a maximum diameter of $40 \mathrm{~mm}$.

sacrificed during exposure of the aneurysm, and reconstructed and anastomosed to the contralateral frontobasal artery. Finally, the aneurysm was trapped with titanium clips. Postoperatively the patient had mild disorientation due to perforator ischemia. This symptom improved gradually, and he had a functionally favorable outcome (modified Rankin scale 1). The aneurysm had disappeared completely on follow-up imaging one year after the surgery (Fig. 2).

Case 5: A 70-year-old woman presented with no neurological deficit. A giant partially thrombosed aneurysm on the right ACA, with a maximum diameter of $40 \mathrm{~mm}$, was found incidentally (Figs. 3 and 4). Direct surgery of the aneurysm was planned. $\mathrm{A}_{3}-\mathrm{A}_{3}$ side-to-side anastomosis was performed to ensure blood flow in the distal ACA prior to treating the aneurysm. The aneurysm was temporarily

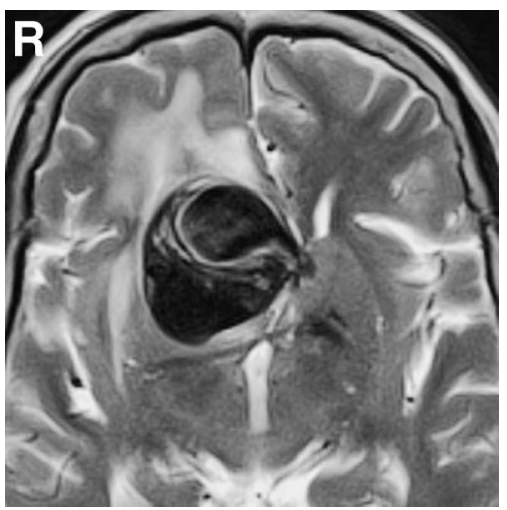

Fig. 4 Case 2. Preoperative axial $T_{2}$-weighted magnetic resonance image showing a giant partially thrombosed distal anterior cerebral artery aneurysm with moderate perifocal edema.

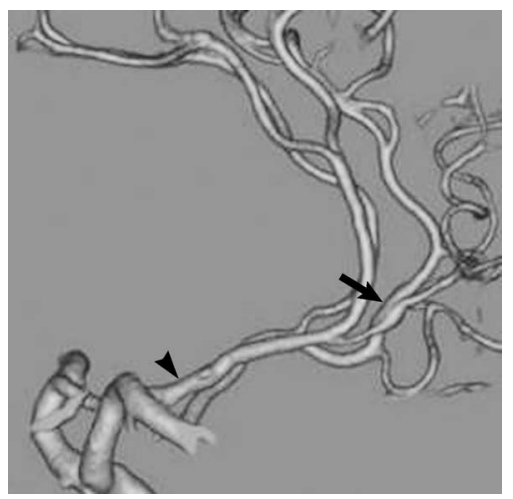

Fig. 5 Case 2. Postoperative lateral three-dimensional computed tomography angiogram showing the giant anterior cerebral artery aneurysm was not visualized, but revealing the reanastomosis site (arrowhead) and the $A_{3}-A_{3}$ anastomosis (arrow).

trapped and removed totally. Reanastomosis of the ACA was then carried out. Postoperatively she had no neurological deficit, and had a functionally favorable outcome (modified Rankin scale 0). The aneurysm had disappeared completely on follow-up imaging one year after the surgery (Fig. 5).

\section{Discussion}

We were able to obtain favorable outcomes by direct surgery of giant AComA or ACA aneurysms using microvascular reconstruction techniques. Cerebral revascularization of the ACA territory may prevent possible ischemic events during necessary temporary clipping for treatment of the aneurysms. A few experienced surgeons have reported the treatment of giant intracranial aneurysms including AComA 
or ACA aneurysms in larger series on cerebral revascularization. ${ }^{4,12)}$ Giant AComA or ACA aneurysms were treated with intracranial-intracranial bypass in a larger series, and the efficacy of intracranial-intracranial bypass for complex brain aneurysms including giant AComA or ACA aneurysms was discussed. ${ }^{12)} \mathrm{A}$ few case reports about the treatment of giant AComA or ACA aneurysms with cerebral revascularization have been reported, and the usefulness of bilateral ACA revascularization with $A_{3}-A_{3}$ side-to-side anastomosis and $A_{3}-R A$ graft- $A_{3}$ anastomosis was emphasized.6,7)

In the present study, insurance bypass of ACA territory was established prior to approaching the aneurysm in all patients and reconstruction of the perforator was performed in one patient with postoperative disorientation due to perforating artery injury. Intraoperative monitoring of higher brain function or detailed preoperative information about incorporated perforators may prevent perforator ischemia in the future.

This study has several limitations. The number of cases was not large and the follow-up periods were relatively short. Surgical strategies for giant AComA or ACA aneurysms may not be able to cure all such aneurysms. Further follow-up studies are needed to confirm the long-term outcome. However, this study found satisfactory outcome after the surgical treatment of giant AComA or ACA aneurysms in spite of the potential risks and complexity. Insurance bypass of the ACA territory is recommended to prepare for surgical treatment of giant AComA or ACA aneurysms.

\section{Conflicts of Interest Disclosure}

The authors have no personal financial or institutional interest in any of the drugs, materials, or devices in the article. All authors who are members of The Japan Neurosurgical Society (JNS) have registered online Self-reported COI Disclosure Statement Forms through the website for JNS members.

\section{References}

1) Barrow DL, Alleyne C: Natural history of giant intracranial aneurysms and indications for intervention. Clin Neurosurg 42: 214-244, 1995

2) Bushe KA, Bockhorn J: Extracranial-intracranial arterial bypass for giant aneurysms. Acta Neurochir (Wien) 54: 107-115, 1980

3) Choi IS, David C: Giant intracranial aneurysms: De- velopment, clinical presentation and treatment. Eur J Radiol 46: 178-194, 2003

4) Drake CG, Peerless SJ: Giant fusiform intracranial aneurysms. Review of 120 patients treated surgically from 1965 to 1992. J Neurosurg 87: 141-162, 1997

5) Hauck EF, Wohlfeld B, Welch BG, White JA, Samson $D$ : Clipping of very large or giant unruptured intracranial aneurysms in the anterior circulation: an outcome study. J Neurosurg 109: 1012-1018, 2008

6) Inoue $\mathrm{T}$, Tsutsumi K, Ohno H, Shinozaki M: Revascularization of the anterior cerebral artery with an A3-A3 anastomosis and a superficial temporary artery bypass using an A3-radial artery graft to trap a giant anterior communicating artery aneurysm: Technical case report. Neurosurgery 57(1 Suppl): E207, 2005

7) Kim K, Mizunari T, Mizutani N, Kobayashi S, Takizawa K, Kamiyama H, Murai Y, Teramoto A: Giant intracranial aneurysm of the anterior communicating artery treated by direct surgery using A3-A3 side-toside anastomosis and A3-RA graft-STA anastomosis. Acta Neurochir (Wien) 148: 353-357, 2006

8) Lawton MT, Hamilton MG, Morcos JJ, Spetzler RF: Revascularization and aneurysm surgery: Classification schema and management strategies in 68 patients. Neurosurgery 38: 83-94, 1996

9) O'Shaughnessy BA, Salehi SA, Mindea SA, Batjer $\mathrm{HH}$ : Selective cerebral revascularization as an adjunct in the treatment of giant anterior circulation aneurysms. Neurosurg Focus 14(3): e4, 2003

10) Pia HW, Zierski J: Giant cerebral aneurysms. Neurosurg Rev 5: 117-148, 1982

11) Quinones-Hinojosa A, Lawton MT: Revascularization with saphenous vein bypasses for complex intracranial aneurysms. Skull Base 15: 119-132, 2005

12) Sanai N, Zadar Z, Lawton MT: Bypass surgery for complex brain aneurysms: An assessment of intracranial-intracranial bypass. Neurosurgery 65: 670-683, 2009

13) Sekher LN, Kalavakonda C: Saphenous vein and radial artery grafts in the management of skull base tumors and aneurysms. Operative Techniques in Neurosurgery 2: 129-141, 1999

14) Spetzler RF, Chater N: Microvascular bypass surgery. Part 2: Physiological studies. J Neurosurg 45: 508-513, 1976

15) Sundt TM Jr: Surgical technique for giant intracranial aneurysm. Neurosurg Rev 5: 161-168, 1982

Address reprint requests to: Hideki Nakajima, MD, Department of Neurosurgery, Osaka City General Hospital, 2-13-22 Miyakojima-Hondori, Miyakojima-ku, Osaka 534-0021, Japan.

e-mail: h-nakajima@hoaspital.city.osaka.jp 